ENRICHMENT OF WHEAT FLOUR BREAD TO ENHANCE NUTRITIONAL AND SENSORY ATTRIBUTES USING SWEET POTATO PUREE

\title{
YVARANI $M^{1}$ AND PARAMESHWARI $\mathrm{S}^{2^{*}}$
}

1: Department of Nutrition and Dietetics, Periyar University, Salem-11, Tamil Nadu, India.

2: Associate Professor, Department of Nutrition and Dietetics, Periyar University, Salem-11, Tamil Nadu, India

*Corresponding Author: Parameshwari. S: E Mail: sparameshwari2009@gmail.com

Received $18^{\text {th }}$ June 2020; Revised 20 ${ }^{\text {th }}$ July 2020; Accepted 25 ${ }^{\text {th }}$ Aug. 2020; Available online $1^{\text {st }}$ May 2021 https://doi.org/10.31032/IJBPAS/2021/10.5.5480

\section{ABSTRACT}

Sweet potato (Ipomoea batatas (L.) is an important tuber crop grown in India. The present study was undertaken to develop nutritious and protein-rich bread by substituting a part of sweet potato puree with whole wheat flour and brown sugar. Sweet potato improves the nutritional value of bread by enhancing the energy, fat, vitamin A, potassium and starch. Potassium and protein content of sweet potato puree is comparatively higher than that of most of the other tubers, potassium helps to reduce blood pressure, improve bone health, boost the nervous system and maintain optimal fluid balance and higher protein content helps to maintain sugar levels, prevent hair damage, and slow down the ageing process, hormone balance and improved immune system. Sweet potato provides an adequate amount of vitamin A in the diet it helps to prevent cancer and heart diseases, reduces the risk of macular degeneration and night blindness, to protect skin and reducing the risk of urinary stones. Sweet potato is also renowned for health beneficial effects such as anti-diabetic effect, antimicrobial effects, hematological effects, wound healing effect, anti-cancer potential, anti-ulcer potential, anti-inflammatory potential, antifungal activity, the effect on the cardiovascular system. This study aimed at the objective of developing bread by incorporating sweet potato puree. The prepared bread subjected to analysis of physical characteristics, sensory evaluation and the accepted variation was subjected to analyze nutritional compositions. It was observed that the sweet potato incorporated bread was drastically rich in energy, protein, fat, starch, vitamin-A and potassium compared to control bread.

Keywords: Bread, Sweet potato puree, Nutritional composition, Value-added snacks 


\section{INTRODUCTION}

Bread is an important staple food and one of the most customary bakery products consumed globally. The major ingredients desired for the making of bread are wheat flour, yeast, brown sugar, milk powder, water, improver, shortening and salt.

Sweet potato (Ipomoea batatas (L.) was cultivated in Central and South America and was later introduced into Africa and is now cultivated throughout tropical Africa. Phenotypic data from field trials conducted in three seasons was also obtained. Genetic diversity in West Africa was found to be $18 \%$ lower than in America.Currently, Sweet Potato cultivation was reported in more than 115 nations [1].

Sweet potato is grown in 117 countries, India ranks third in Asia and 10th in the world. However, India accounts for just 1.51 $\%$ of the area. Although sweet potato is cultivated in India in almost all the states, major production comes from Orissa (23 per cent) followed by Kerala (19 per cent), West Bengal (15 per cent) and Uttar Pradesh (14 per cent) [2].

Sweet potato production was reported to be 112.8 million tons (in 115 countries) in 2017, and China is the leading producer, followed by Nigeria and Tanzania, Indonesia, and Uganda [1].
Traditional sweet potato products are having momentous role in income generation in small-scale businesses and entrepreneurs run by women. In developing nations such as Uganda and other countries, dehydrated and minimally processed foodstuffs from Orange Fleshed Sweet Potato have recognized as the momentous for domestic utilization and household markets [3].

Orange-fleshed sweet potato is a good source of non-digestible dietary fiber, specific minerals, different vitamins, and antioxidants $[4,5]$.

One of the easiest ways to introduce more Vitamin A into the diet is by consuming the carotene-rich plant-based foods like sweet potato. This is a good source of Carotenoids, and they readily convert into retinol in human body. The supplementation of 100-150 g of the Orange Fleshed Sweet Potato in human diet can prevent Vitamin A Deficiency and radically diminish maternal mortality [6].

Sweet potatoes have numerous health benefits, such as anti-mutagenic, anti-diabetic, and hepatic and cardio-protective effects, attributable to their phytochemical content. Despite the importance of sweet potatoes, few large-scale systematic studies have been conducted on 
their genomics, transcriptomics, proteomics, or metabolomics [7].

Albeit the low utilization rate of sweet potato in most developing countries where it is abundantly cultivated, its utilization has been fully diversified in industrialized countries for the production of liquid and semi-solid food products such as beverages, soups, baby foods, ice-cream, baked products, restructured fries, breakfast cereals and various snack and dessert items. This is because processing technologies for converting the roots into purees and powders (since its original form does not provide the functionality required in bakery products especially read since it lacks gluten) that can be used as functional food ingredients are readily available [8]. Thus, the present study is aimed to study the effect of sweet potato puree on the physical, sensory and nutritional indicators of bread quality.

\section{MATERIALS AND METHODS}

The study was conducted in the Department of Nutrition and Dietetics, Periyar University Salem, Tamil Nadu. The ingredients required for the development of bread by the use of sweet potato, whole wheat flour, brown sugar, butter and yeast procured from the local market, Salem, Tamil Nadu, India. The sweet potato was purchased and washed with cold water to remove the dirt and sand particles. Drain out the water from the sweet potato and keep the sweet potato in a cleansed vessel. After washing, the sweet potatoes are put into the idly cooker for steaming. It takes 25-30 minutes to cook well. Then sweet potato was taken from the idly cooker keep it aside and it allows cooling it in room temperature completely. After cooling, the sweet potato to make a puree by using the blender. The sweet potato puree was standardized using three different variations named as V1, V2 and V3. The three different variations of sweet potato puree were taken separately and add $30 \mathrm{~g}$ of butter, and mixing the whole wheat flour $50 \mathrm{~g}$ with salt $5 \mathrm{~g}$, brown sugar $15 \mathrm{~g}$ and add in the instant yeast to pinch. Mix it well and adding water in intervals kept in bread making oven for $180^{\circ} \mathrm{C}$ for 1 hour. The loaves were allowed to cool for one hour, slice it nicely and packaged in low-density polyethene bags and kept at $24 \pm 2{ }^{\circ} \mathrm{C}$.

\section{RESULTS AND DISCUSSION}

\section{Development of the sweet potato} puree incorporated bread.

The sweet potato puree added to bread in different variations viz. V1, V2 and V3 and other mixing agents also measured in different quantity and combined in different variations. The composition of ingredients used for 
developing bread of different variations are shown in Table 1.

2. Physical characteristics of the developed bread

The physical characteristics of sweet potato puree incorporated bread viz. height, weight and diameter were assessed as per the standard procedure (Table 2). Compared to control bread, bread formulated with sweet potato puree showed an increase in height, weight and diameter.

3. Sensory evaluation of the sweet potato puree incorporated bread

The method of Bakare, et al, (2016)

[9] was adopted slight modifications for selection of panelists for sensory evaluation of the breads. Forty volunteers comprising of staff and students of Nutrition and Dietetics Department, Periyar University, Salem were selected on the basis of a criteria namely, good health, non-allergic to wheat/sweet potato, willingness to participate, and passion for bread. The developed products were evaluated using a 9-point Hedonic scale rating where 9 represented like extremely and 1 , dislike extremely for each attribute evaluated. Statistical analysis of the sensory evaluation of the developed bread is presented in the Table 3.

The results of the above table revealed that the mean score obtained for the colour of V1 and V3 were found to be the maximum score $\left(6.53 \pm 0.47^{\mathrm{c}}\right.$ and $8.61 \pm 0.26^{\mathrm{bc}}$ ) than control and V2. Mean score of texture was high (8.74 \pm $0.12^{\mathrm{bc}}$ ) in V3 compared to control and other variations. The results revealed that the mean score obtained for the flavour of $\mathrm{V} 3$ was found to be superior $\left(7.86 \pm 0.76^{\mathrm{a}}\right)$ compared to control and other variations. Variation 3 had the maximum mean scores of $8.64 \pm$ $0.22^{\mathrm{bc}}$ for mouthfeel, thus confirming that addition of sweet potato at $50 \mathrm{gm}$ is more acceptable whereas V1 and V2 had scored lower than V3 due to the less addition of other ingredients which affected the mouthfeel of the end product. Mean taste scores of control bread prepared with wheat flour, brown sugar, butter, yeast were low $\left(4.85 \pm 0.42^{\mathrm{bc})}\right.$ compared with variation $1,2 \& 3\left(4.16 \pm 0.42^{\mathrm{a}}, 5.22 \pm\right.$ $\left.0.42^{\mathrm{a}} \& 7.55 \pm 0.74^{\mathrm{a}}\right)$ respectively. As an overall result, the overall acceptability of the sweet potato puree (50gm) bread of variation 3 was high $\left(8.22 \pm 0.12^{\mathrm{bc}}\right)$ on a hedonic scale. 
Results on Duncan Multiple Range test showed that there was a significant difference $(\mathrm{p}<0.05)$ between control and the different variations of bread on colour, texture, flavour, mouthfeel, taste and overall acceptability.

4. Nutritional composition of accepted variation of the developed bread

Based on the physical characteristics and sensory evaluation of the developed bread, $50 \mathrm{~g}$ of sweet potato puree incorporated bread Variation 3 was highly accepted and hence the nutrient analysis variation 3 was done in the accepted variation are shown in

Table 4, Figure 1.

Table 5 shows that the nutrient level of the accepted variations $50 \mathrm{~g}$ of sweet potato puree incorporated bread (variation - 3) and control bread. The moisture content of the sweet potato puree bread was $32.27 \%$ which is lower than the control bread. There is a high chance in the calorie content between the sweet potato puree bread and control bread because sweet potato contain high amount of calories. The carbohydrate content of the sweet potato puree incorporated bread was $19.1 \mathrm{~g} / 100 \mathrm{~g}$ which is lower than the control bread. The fat content of the sweet potato puree incorporated bread was $28.19 \mathrm{mg} / 100 \mathrm{~g}$ which is higher than the control bread. The dietary fibre content of the sweet potato puree bread was $0.22 \mathrm{~g} / 100 \mathrm{~g}$ which is lower than the control bread. Total starch content of the sweet potato puree bread $47.27 \mathrm{mg} / 100 \mathrm{~g}$ which is higher than the control bread. In this sweet potato puree incorporated bread was $12.192 \mathrm{mg}$ of vitamin A. Calcium level present in the developed bread was $0.15 \mathrm{mg}$ whereas the control bread. There is a slight change in the calcium content between the developed bread and control bread. The potassium content of the sweet potato puree incorporated bread was $14.29 \mathrm{mg} / 100 \mathrm{~g}$, it was higher than the control bread. The sodium content of the sweet potato puree incorporated bread contains $0.68 \mathrm{mg} / 100 \mathrm{~g}$.

In contrast, the control bread does not have any vitamin A content which shows that sweet potato puree incorporated bread will improve the vitamin A level.

5. Cost calculation of the developed 


\section{food products}

The cost calculation for the production of $100 \mathrm{gm}$ of developed bread revealed that the total production cost $(100 \mathrm{~g})$ was Rs.30 (10 pieces) by incorporating sweet potato puree, whole wheat flour, brown sugar, butter and yeast. It was evident that the prepared bread was more economical and affordable when compared with commercial bread available in the markets.

Table 1: Ingredients for sweet potato puree incorporated bread

\begin{tabular}{|c|c|c|c|c|}
\hline Ingredients & Control & Variation - 1 & Variation -2 & Variation -3 \\
\hline Whole wheat flour & $100 \mathrm{~g}$ & $70 \mathrm{~g}$ & $60 \mathrm{~g}$ & $50 \mathrm{~g}$ \\
\hline Sweet potato puree & - & $30 \mathrm{~g}$ & $40 \mathrm{~g}$ & $50 \mathrm{~g}$ \\
\hline Brown sugar & $15 \mathrm{~g}$ & $15 g$ & $15 g$ & $15 g$ \\
\hline Butter & 30g & 30g & 30g & 30g \\
\hline Yeast & 1 pinch & 1 pinch & 1 pinch & 1 pinch \\
\hline Salt & $5 g$ & $5 g$ & $5 g$ & $5 g$ \\
\hline Water & $50 \mathrm{ml}$ & $50 \mathrm{ml}$ & $50 \mathrm{ml}$ & $50 \mathrm{ml}$ \\
\hline
\end{tabular}

Table 2: Physical characteristics of the sweet potato puree incorporated bread

\begin{tabular}{|c|c|c|c|}
\hline Samples & Height $(\mathbf{c m})$ & Weight $(\mathbf{g})$ & Diameter $(\mathbf{c m})$ \\
\hline Control bread & 24 & 150 & 3.1 \\
\hline Variation 1 & 23 & 170 & 2.6 \\
\hline Variation 2 & 25 & 180 & 2.5 \\
\hline Variation 3 & 28 & 200 & 2.9 \\
\hline
\end{tabular}

Table 3: Statistical analysis of sensory evaluation of the developed bread

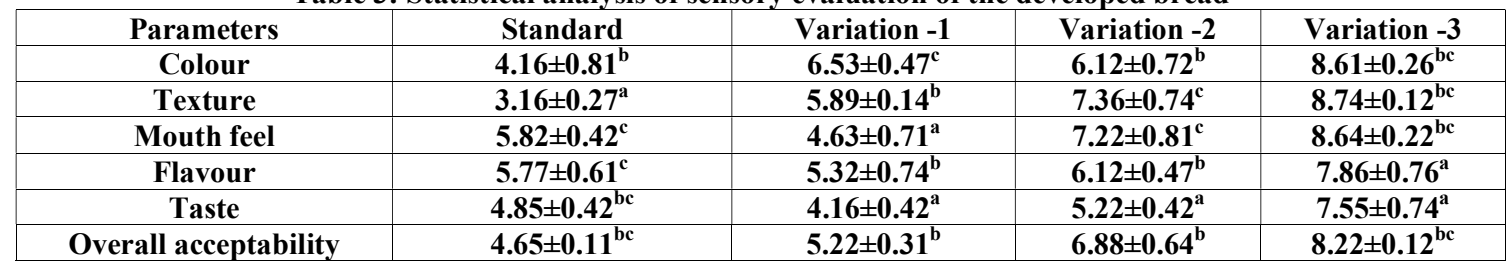

Values are Mean \pm SD of triplicate determination. Samples with different superscripts within the same column were significantly $(\mathbf{p} \leq \mathbf{0 . 0 5})$ different

Table 4: Nutritional composition of the accepted variation of the developed bread

\begin{tabular}{|c|c|c|c|c|}
\hline S. No. & Nutrients & $\begin{array}{c}\text { Control } \\
\text { bread }\end{array}$ & $\begin{array}{c}\text { Sweet potato puree } \\
\text { incorporated bread } \\
\text { (variation }-3)\end{array}$ & $\begin{array}{l}\text { Deficient } \\
\text { or } \\
\text { excess }\end{array}$ \\
\hline 1 & Moisture (g/100g) & 41.6 & 32.27 & -9.33 \\
\hline 2 & Ash (g/100g) & 0.5 & 3.97 & +3.47 \\
\hline 3 & Energy(kcal/100g) & 251 & 395 & +144 \\
\hline 4 & Carbohydrate (g/100g) & 47.6 & 19.1 & -28.5 \\
\hline 5 & Protein (g/100g) & 9.6 & 16.25 & +6.65 \\
\hline 6 & Fat (g/100g) & 1.5 & 28.19 & +26.69 \\
\hline 7 & Dietary fibre (g/100g) & 4.0 & 0.22 & -3.78 \\
\hline 8 & Total starch (mg/100g) & 20.3 & 47.27 & +26.97 \\
\hline 9 & Vitamin A (mg/100g) & - & 12.192 & +12.192 \\
\hline 10 & Calcium (mg/100g) & 1.86 & 0.15 & -1.71 \\
\hline 11 & Potassium (mg/100g) & 5.0 & 14.29 & +9.29 \\
\hline 12 & Sodium (mg/100g) & 17.0 & 0.68 & -16.32 \\
\hline
\end{tabular}




\section{Nutritional composition of the accepted variation of developed bread}

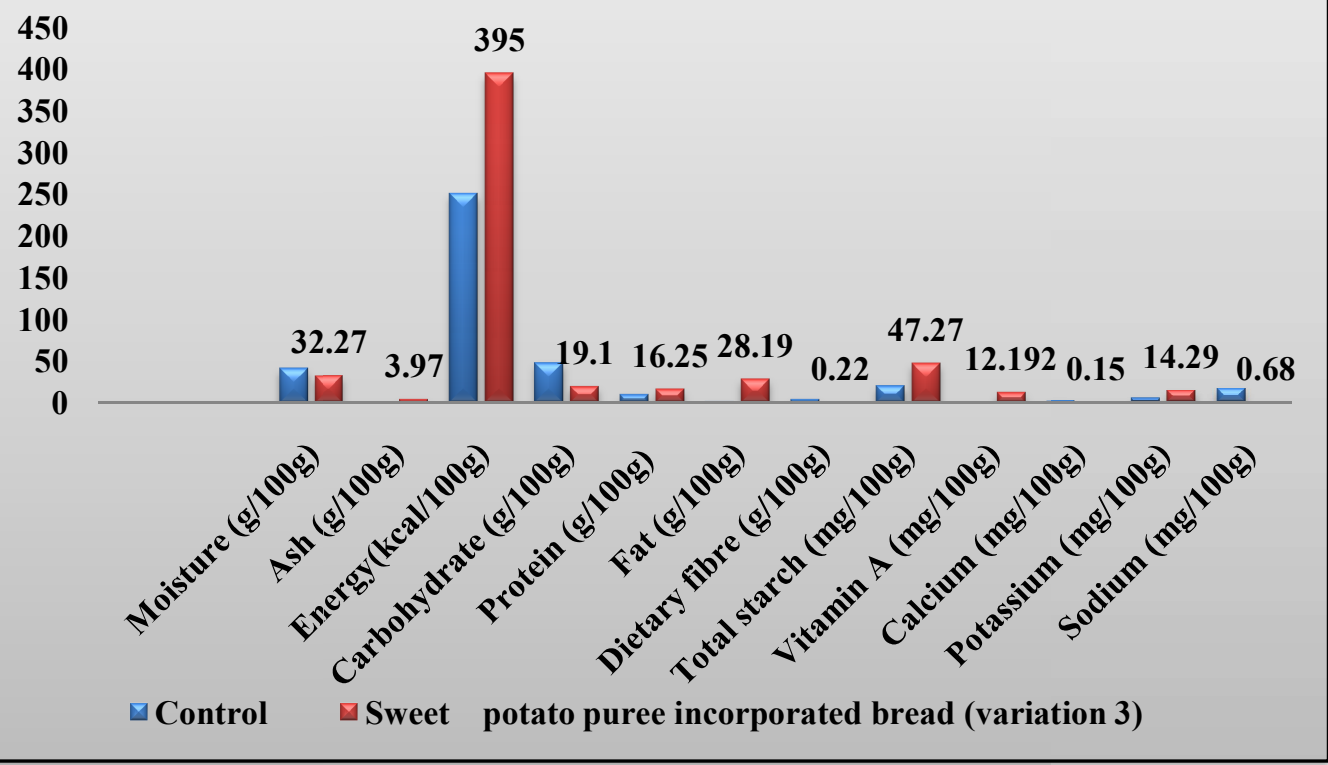

Figure 1: Nutrient composition of the accepted variation of developed bread

\section{CONCLUSION}

The present study has shown that, the incorporation of sweet potato puree resulted in increased energy, protein, fat, starch, vitamin A and potassium in the bread. Bread with $50 \mathrm{~g}$ of sweet potato puree added was highly acceptable by the consumers. This sweet potato puree for incorporation in bread could permit a reduction of formulation cost without affecting sensory attributes of the developed product to which the consumer familiarized. Its nutritional and functional properties have been reviewed and found best among all tubers. This is not only advantageous to increase nutritional composition, but also improves the economy of non-wheat producing countries by reducing the expenditure of importation of wheat.
Regular consumption of sweet potato helps in protecting our body from free radical damage and chronic disease. It also promotes gut health, cancer-fighting properties, bone and teeth health, support to healthy vision, improves brain functions and supports the immune system.Further studies are required to determine the effect of fermentation on the glycemic index, nutritional composition and antioxidant potentials of this sweet potato puree incorporated bread.

\section{Acknowledgement}

The authors are highly thankful to the Department of Nutrition and Dietetics, Periyar University, Salem and Nutri Science Research Laboratory Pvt. Ltd., (NABL Accredited Laboratory), Salem for provided necessary facilities and support to carry out 
this research work.

\section{Conflict of Interest:}

The authors declare that they have no conflict of interest.

\section{Funding support:}

The authors declare that they have no funding support for this study

\section{REFERENCE}

[1] FAOSTAT, Food Agriculture and Organization (FAOSTAT). 2019, http://www.fao.org/faostat/en/\#data/QC

[2] Food and Agricultural Organization, FAO Statistics, Food and Agricultural Organization, 2016.

[3] Sweet Potato Knowledge Portal, Sweet potato processing and marketing. https://www.sweetpotatokno wledge.org/topics/processing-and-market ing/

2018.

[4] Endrias, D, Negussie, R., \& Gulelat, D., Comparison of three sweet potato (Ipomoea Batatas (L.) Lam) varieties on nutritional and anti-nutritional factors. Global Journal of Science Frontier Research: D Agriculture and Veterinary, 16(4), 2016, 1920-11.

[5] Rodrigues, N. R. , Barbosa, J. L. , \& Barbosa, M. I. M. J, Determination of physico-chemical composition, nutritional facts and technological quality of organic orange and purple-fleshed sweet potatoes and its flours. International Food Research Journal, 23(5), 2016, 1920-11.

[6] International Potato Center, Sweet potato in Africa, 2017, Retrieved from https://cipotato.org/research/sweetp otato-in-africa/

[7] Soo-Yun Park, So Young Lee, Jung Wook Yang, Joon-Seol Lee, Sung-Dug Oh, Seonwoo Oh, Si Myung Lee, Myung-Ho Lim, Soon Ki Park, Jae-Seon Jang, Hyun Suk Cho \& Yunsoo Yeo, "Comparative analysis of phytochemicals and polar metabolites from colored sweet potato (Ipomoea batatas L.) tubers", Food Science and Biotechnology, 25, 2016, 283-291.

[8] Truong VD, Avula RY, Sweet potato purées and dehydrated forms for functional food ingredients. In: Sweet potatoes: Post harvest Aspects in Food, Feed and Industry (Ray RC, Tomlins KI, editors). New York: Nova Science Publishers, Inc, 2010, 117-161.

[9] Bakare, H. A.,Osundahunsi,O.F, and Olusanya,J.O, Rheological, baking, and sensory properties of composite bread dough with breadfruit (Artocarpus communis Forst) and wheat flours, J. Food Sci. Nutr, 4(4), 2015, 573-587. 